\title{
Sediment response to catchment disturbances
}

\author{
Philip N. Owens • Ellen L. Petticrew • \\ Marcel van der Perk
}

Received: 31 March 2010 /Accepted: 31 March 2010/Published online: 28 April 2010

(C) The Author(s) 2010. This article is published with open access at Springerlink.com

\section{Introduction}

The surface of the planet undergoes a constant battle for balance between uplift and erosion. Plate tectonics cause land to be created and mountains to be born, while weathering and erosion act to lower the land surface. Rivers transport the products of weathering and erosion to storage points, or sinks; the ultimate sink being the deep oceans. For a given landscape, an equilibrium is reached whereby the rates of sediment distribution between sources and sinks are fairly constant. In the case of a river channel, the amount of water and sediment moved through a landscape is balanced by the energy available to do this, such that a change in either of the two generates adjustments in stream power. A change in environmental conditions often results in a response, the magnitude of which is a function of the type and intensity of "disturbance" to the system. In the case of the river channel, this might manifest itself in the form of channel aggradation or degradation, whereby sediments are either deposited or eroded in response to changes in available energy or sediment supply.

Responsible editor: Philip N. Owens

\section{P. N. Owens $(\bowtie)$}

Environmental Science Program and Quesnel River Research Centre, University of Northern British Columbia,

Prince George, BC V2N 4Z9, Canada

e-mail: owensp@unbc.ca

\section{E. L. Petticrew}

Geography Program and Quesnel River Research Centre, University of Northern British Columbia,

Prince George, BC V2N 4Z9, Canada

M. van der Perk

Department of Physical Geography, Utrecht University, P.O. Box 80115, 3508 TC Utrecht, The Netherlands
Changes to a landscape are both natural and anthropogenic. In terms of landscapes, we tend to think of a "disturbance" event as one that is fairly extreme and produces a measureable response in the rate or type of processes occurring in the landscape. Examples of natural disturbances include earthquakes, volcanic activities and wildfires. Examples of anthropogenic disturbances include deforestation, intensive agriculture, urbanization, dam construction and gravel mining. Typically, in natural systems, the types of geomorphic responses to these events include increased rates of sediment mobilization (i.e., soil erosion, mass movements), transport (i.e., delivery to and within river channel systems) and deposition (i.e., in floodplains, lakes, estuaries). A good example is the 1980 eruption of Mount St Helens volcano, USA, where annual suspended sediment yields after the eruption were as much as 500 times greater than typical background levels. Even 20 years after the eruption, average suspended sediment yields from the debris-avalanche deposits remained 100 times $\left(10^{4} \mathrm{t} \mathrm{km}^{-2}\right.$ year $\left.^{-1}\right)$ above typical background levels $\left(10^{2} \mathrm{t} \mathrm{km}^{-2}\right.$ year $\left.^{-1}\right)$ (Major et al. 2000). There are, however, examples where fairly major disturbances have not produced the response expected. For example, Petticrew et al. (2006) describe the situation where there was no significant change in fine-grained sediment transport and storage in the first two years following a severe wildfire in a mountainous basin in British Columbia.

\section{Conceptual model of response to disturbance}

Figure 1 shows a conceptual diagram of changes in sediment movement in a river basin, as represented by fluvial sediment yield, in response to disturbances or "forcings" (Viles et al. 2008). Before the disturbance, the landscape is in some form of (dynamic) equilibrium, such 


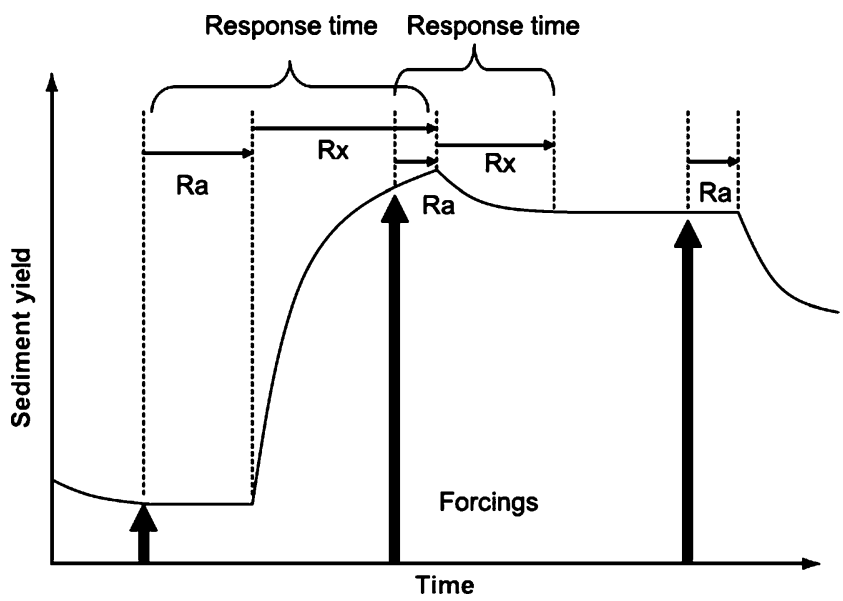

Fig. 1 A geomorphological disturbance model. $R a$ reaction time, $R x$ relaxation time. (Adapted from Viles et al. 2008)

that annual sediment yields fluctuate (i.e., from year to year, perhaps reflecting variations in precipitation) but over the long term they are fairly constant. A disturbance (e.g., wildfire, deforestation) or forcing occurs, but there may not be an immediate response in sediment yields, as it may take some time for sediment to be mobilized and transported to a river channel. The time taken for a noticeable increase in sediment yield is the reaction time ( $\mathrm{Ra}$, see Fig. 1) and the additional time for a new level of equilibrium to be reached is the relaxation time ( $\mathrm{Rx}$, see Fig. 1): the response time being the sum of $\mathrm{Ra}$ and $\mathrm{Rx}$. There are two important points to note from this model. First, there is a time lag between disturbance/forcing and reaction, which is likely to be a function of the topography and size of the river basin: a smaller basin will react more quickly than a larger basin. This means that we may not know how a landscape or river basin responds to a disturbance for some time after the action, maybe years or decades. Second, the level of equilibrium reached after disturbance may not be the same as that before the event: the system has changed and it may not be possible to revert back to the original condition. The latter point is particularly relevant when we try to remediate environmental systems.

\section{Types of response to disturbances}

The disturbance response of natural systems can be characterized into three categories as presented in Förstner and Owens (2007). The sediment responses can be:

- Too much sediment

- Too little sediment

- Changes in sediment composition and quality

While most of the world's major basins experience each of these sediment responses over long time scales, on the shorter term (decades) and on local scales (channel reach, reservoir or estuary), typically only one or two of these responses becomes a societal concern.

\subsection{Too much sediment}

Areas within a river basin where there is too much sediment, from a societal perspective, are locations where the sediment concentration is too high, such as the intakes of turbines at hydroelectric power plants, and/or where the volume of deposited sediment is too large. In the case of the latter, problem areas include canals, upstream of dams and impoundments, ports and harbours. Too much sediment, especially fine-grained sediment (i.e., clay, silt and fine sand) can also be a problem for sensitive aquatic habitats such as fish-spawning gravels as the fine sediment blocks the gravels, reducing oxygen supply and increasing fish egg and larval mortality. Unlike ports and harbours where the amount of sediment requiring dredging can be thousands of cubic meters, the amount of sediment needed to detrimentally influence aquatic habitats can be fairly small, and it is often the type (i.e., fine-grained) and timing (i.e., during important reproductive times) that are important. This underlines that it is not just the amount of sediment that is important but also the timing of sediment transport and storage.

There are numerous examples of the amounts and costs involved with removing sediment. One of the best documented examples is the port of Hamburg, Germany, which spends on the order of 30 million Euros each year to dredge and treat between 2 and $5 \times 10^{6} \mathrm{~m}^{3}$ of sediment, much of which is contaminated, thereby increasing the complexity of the problem and the cost (Netzband et al. 2002). Hamer et al. (2005) state that the Netherlands and Germany dredge between 30 and $50 \times 10^{6} \mathrm{~m}^{3}$ of sediment annually.

\subsection{Too little sediment}

While a significant amount of attention and resources are given to dealing with the issue of too much sediment, in many situations there are problems associated with too little sediment. Again, it is important to recognize that it is too little from the perspective of society. One of the major causes of the reduction in sediment fluxes is the construction of dams and impoundments which reduce the supply of sediment to downstream reaches of a river. The natural supply and flow of sediment along a river system are interrupted and sediment that would normally move through a river network is deposited upstream of the impoundment. Downstream of the impoundment, there can be problems due to a dramatic reduction in sediment supply which often leads to "hungry waters", whereby the 
river compensates for the reduction in sediment load by downcutting and lateral erosion (Kondolf 1997). In turn, this can lead to pronounced changes in the hydromorphology of the river system.

A good example is the Ebro River basin in Spain, where about 190 dams now impound almost $60 \%$ of the annual runoff in the basin. Total annual sedimentation in the reservoirs is estimated at $15 \times 10^{6} \mathrm{~m}^{3}$ year ${ }^{-1}$. As a result of these impoundments, the total annual sediment load to the coastal zone at present is estimated to be only $3 \%$ of the sediment load at the start of the 20 th century, and most of this sediment is now derived from channel sources compared to hillslope sources (Batalla 2003; Vericat and Batalla 2006). These reductions in sediment supply to downstream river reaches, estuaries and the coastal zone can result in the loss of important habitats such as wetlands, mud flats and salt marshes, which are particularly sensitive to change (Batalla 2003). Downstream of the Hoover Dam on the Colorado River in USA, the riverbed had degraded by $7.5 \mathrm{~m}$ within 13 years of dam closure and this erosion has affected $120 \mathrm{~km}$ of the river during that period (Williams and Wolman 1984). Downcutting of river channels can undermine structures such as buildings, roads and bridges, and in some cases lead to loss of life, as demonstrated by the collapse of a bridge on the Duero River in Portugal (Batalla 2003). Furthermore, Leopold (1997) describes the situation downstream of the Aswan Dam (Egypt) where 15-19\% of the habitable land of the Nile delta could be gone within 60 years. This is due to a net shrinking of the delta surface resulting from a lack of sediment supply from upstream sources (to balance that sediment lost by natural coastal erosion), resulting in the potential displacement of $15 \%$ of the population of Egypt.

\subsection{Changes in sediment composition and quality}

There are abundant examples which demonstrate how sediment quality has been affected in response to human activities. A well-known example is the widespread particulate phosphorus increase in many agricultural river basins in the world. In these basins, fertilizer use and accelerated soil erosion on agricultural land have resulted in elevated sediment inputs and phosphorus concentrations in stream and lake beds. Streambed sediments that contain excess phosphorus cause increased dissolved phosphorus concentrations in streams during baseflow conditions (e.g., McDowell et al. 2001; van der Perk et al. 2007). In lakes and reservoirs, release of phosphorus from bottom sediments (also referred to as internal loading) may prevent improvements in lake water quality, even when the external phosphorus inputs have been reduced (e.g., Welch and Cooke 1995; Søndergaard et al. 2003).

Besides sediment quality deterioration caused by contaminant inputs from diffuse sources, sediment contamination is most commonly noticeable downstream from discrete point sources, such as mine tailings and industrial and domestic waste water discharges. For example, Fig. 2 shows how the metal content of fluvial sediment deposited on floodplains in the Aire catchment, UK, are elevated downstream of a large industrial and urbanized area (Beal site) relative to a more natural site upstream of this area (Silsden site). The metal content is increased by a factor up to 10 or more above local background concentrations. The elevated concentrations are clearly related to industrialization from the early 19th century and the peak of the contamination was in the 1930 s just before the beginning of the Second World War. After a lower contamination peak in the late 1960 s-early 1970 s, the sediment quality gradually improved as a result of pollution control measures to reduce
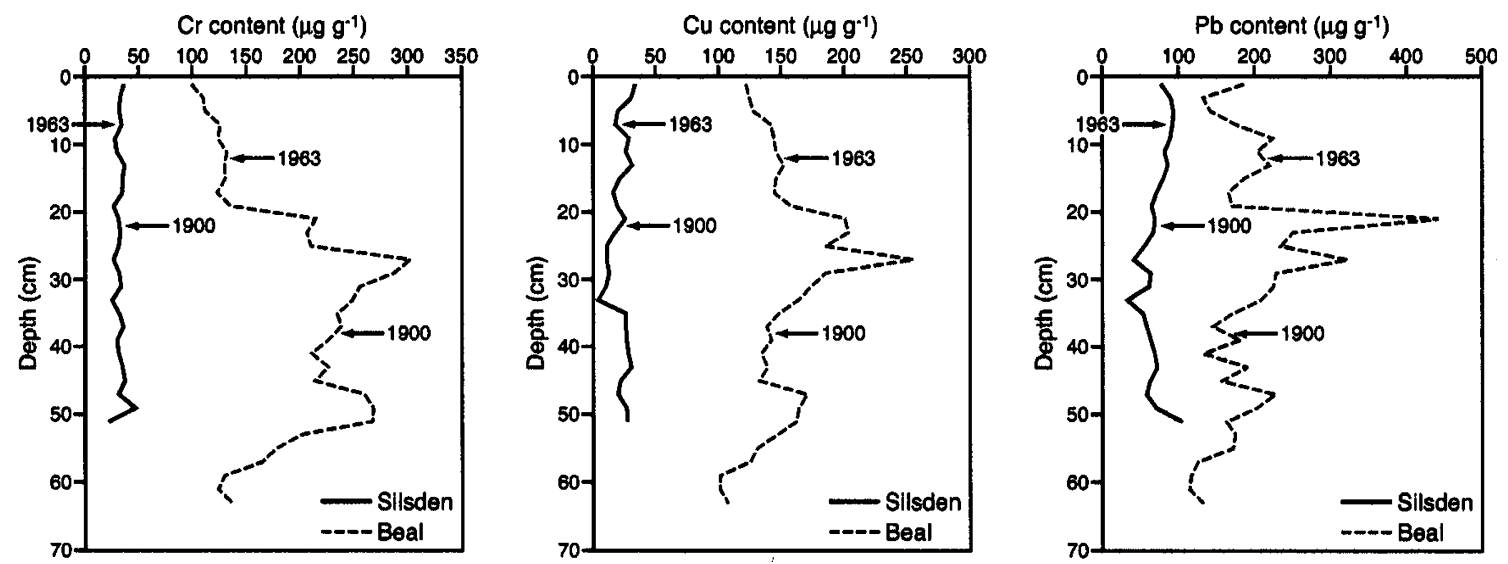

Fig. 2 Downcore changes in the metal content of floodplain sediment for cores collected upstream (Silsden) and downstream (Beal) of the city of Leeds. Chronology was established from ${ }^{137} \mathrm{Cs}$ and ${ }^{210} \mathrm{~Pb}$ dating. (Adapted from Owens and Walling 2003) 
metal loads from waste water discharges. Nevertheless, the metal concentrations downstream have remained considerably elevated compared to the upstream site. A similar history of metal contamination has been observed in floodplain sediments of the River Rhine in the Netherlands (Middelkoop 2000).

Like phosphorus, metals and other sediment-associated contaminants stored in streambed and floodplain sediments may become secondary sources of pollution and so pose a risk to downstream areas (Förstner et al. 2004; Heise and Förstner 2006). This was also demonstrated by a modeling study performed by Coulthard and Macklin (2003) who simulated the movement of sediment-associated metals downstream of a mine site in the catchment of the River Swale in the UK. Although the area had been mined since Roman times, intense mining took place between 1700 and 1900 AD. Channel migration and the remobilization of contaminated bank and floodplain deposits result in sediment and contaminant transfer down the river network. Widespread contamination has been shown to persist for hundreds of years long after mine closure, with floodplain deposits locally more contaminated than mine sites themselves.

\section{Advancement in understanding sediment response to disturbances}

The majority of the papers in this thematic issue of the Journal of Soils and Sediments stem from a session at the European Geosciences Union conference in Vienna, Austria, in 2009, organized by the authors. The papers describe case studies of the types of sediment response to disturbances within the landscape, focusing, in particular, on river basins or catchments. These case studies help to further our understanding of the complex interaction between alterations in the catchment system and the adjustment of sediment amounts and composition. The brief discussion above, while not exhaustive, places these examples within a broader context.

\subsection{Sediment quantity}

Slaymaker (2010) provides an overview of how human activity has modified landscapes in mountain areas throughout the world, with the main exception of the polar mountain regions. He shows that human activities and disturbances (e.g., deforestation, agriculture, resource extraction, urbanization, infrastructure development) probably have a greater influence on erosion rates and sediment transport in rivers than climate changes.

Vanmaercke et al. (2010) collected detailed data on sediment transport dynamics for a catchment in the highlands of northern Ethiopia - an area with a long history of land degradation and soil erosion in response to deforestation, high stocking densities and rapid population growth. In this catchment, despite the introduction of soil conservation measures to mitigate the effects of human disturbance, suspended sediment yields are still high (500$6500 \mathrm{t} \mathrm{km}^{-2}$ year $^{-1}$ ). The majority of sediment export occurs during a few intense flood events, and the authors suggest that in order to mitigate sediment transfers at the catchment scale, it is necessary to consider ways to mitigate high water flows in channels as well as hillslope erosion rates.

Middelkoop et al. (2010) use a range of methods to both hindcast and forecast sediment accumulation in the floodplain of the Rhine Delta. A comparison of middle Holocene (6000-3000 BP), late Holocene (3000-1000 BP), the period after 1350 when embankment of the floodplain occurred and post-1850s engineering of the river channel indicate the importance of historic land uses and response to river engineering works in modifying sediment fluxes. While maximum accumulation occurred in the late Holocene, conditions following the embankment of the floodplain resulted in a reduction of sediment trapping in the delta $\left(1.6 \times 10^{9} \mathrm{~kg} \mathrm{year}^{-1}\right)$. These rates exceeded the estimated deposition following man-made channelization of the river $\left(1.15 \times 10^{9} \mathrm{~kg}\right.$ year $\left.^{-1}\right)$. Several future scenarios were modeled to predict the combined effects of climate and land use changes indicating sediment trapping rates could potentially double.

Slattery et al. (2010) investigate whether modern fluvial sediment input from the Trinity River, Texas, USA, is adequate to sustain sedimentation in the delta. This delta, which comprises an intricate system of anastomosing channels, levees, lakes and marshes, suffers from subsidence and wetland loss. By means of radiocarbon dating of shell fragments recovered from two sediment cores, mean Holocene sediment accumulation rates were found to be 1.2 and $1.8 \mathrm{~mm}$ year $^{-1}$, whereas modern fluvial sediment input to the Trinity River delta occurs at a rate of approximately $0.4 \mathrm{~mm}$ year $^{-1}$.

Neary et al. (2010) deal with the effects of streamside management zones in harvesting of a eucalypt forest on a Tasmanian farm (Australia). While efforts to address the effects of a single disturbance are of interest, it is often the case that other factors influence the response simultaneously, or that the forcing functions are not of the frequency or magnitude expected in the time period. On this working farm, the cumulative effect of cattle grazing, road erosion, managed harvesting and the effect of some frequent but low-intensity rainstorm events are presented. In the set of conditions sampled, the upstream effects of cattle and road erosion result in larger stream turbidity responses than the areas harvested with stream side buffers. 


\subsection{Sediment quality}

Blake et al. (2010) show how severe wildfires in Greece increased sediment mobilization and yields on hillslopes. Importantly, they also demonstrated that the wildfires not only increased the particulate phosphorus delivery from hillslopes to receiving river channels but that the bioavailability of $\mathrm{P}$ in the mobilized sediment also increased due to the wildfires, which could pose a long-term threat to aquatic ecosystems.

Byrne et al. (2010) examine the environmental legacy of the Dylife lead/zinc mine in the central Wales mining district. The bed sediments of the Afon Twymyn are found to be grossly contaminated with metals derived from the Dylife mine, with concentrations exceeding the draft Environment Agency of England and Wales sediment quality criteria at most sample locations. The importance of the assessment of metal mobility is underpinned as bioavailable metal phases are regarded as a serious risk to the target of "good" ecological status as defined in the European Water Framework Directive.

\section{Conclusions}

As scientists, managers and policy makers interested in sediment, we are concerned with understanding and mitigating how sedimentary systems respond to environmental changes or disturbances. The examples presented in this thematic issue of the Journal of Soils and Sediments help to advance our understanding of such issues and show that the link between disturbance and response may not be straightforward. Indeed, one area of research that requires further attention is how landscapes respond to cumulative effects (Gunn and Noble 2009) because, in reality, most landscapes are affected by multiple stressors (both in time and space) which are unlikely to act in complete isolation from one another.

Open Access This article is distributed under the terms of the Creative Commons Attribution Noncommercial License which permits any noncommercial use, distribution, and reproduction in any medium, provided the original author(s) and source are credited.

\section{References}

Batalla RJ (2003) Sediment deficit in rivers caused by dams and instream gravel mining. A review with examples from NE Spain. Cuaternario y Geomorfología 17:79-91

Blake WH, Theocharopoulos SP, Skoulikidis N, Clark P, Tountas P, Hartley R, Amaxidis Y (2010) Wildfire impacts on hillslope sediment and phosphorus yields. J Soils Sediments. doi:10.1007/ s11368-010-0201-y, this issue
Byrne P, Reid I, Wood PJ (2010) Sediment geochemistry of streams draining abandoned lead/zinc mines in central Wales: the Afon Twymyn. J Soils Sediments. doi:10.1007/s11368-009-0183-9, this issue

Coulthard TJ, Macklin MG (2003) Modeling long-term contamination in river systems from historical metal mining. Geology 31:451-454

Förstner U, Owens PN (2007) Sediment quantity and quality issues in river basins. In: Westrich B, Förstner U (eds) Sediment dynamics and pollutant mobility in rivers. Springer-Verlag, Berlin, pp 1-15

Förstner U, Heise S, Schwartz R, Westrich B, Ahlf W (2004) Historical contaminated sediments and soils at the river basin scale - examples from the Elbe River catchment area. J Soils Sediments 4:247-260

Gunn J, Noble BF (2009) Integrating cumulative effects in regional strategic environmental assessment frameworks: lessons from practice. J Environ Assess Policy Manag 11:267-290

Hamer K, Hakstege P, Arevalo E (2005) Treatment and disposal of contaminated dredged sediments. In: Lens P, Grotenhuis T, Malina G, Tabak H (eds) Soil and sediment remediation. IWA Publishing, London, UK, pp 345-369

Heise S, Förstner U (2006) Risks from historical contaminated sediments in the Rhine basin. Water Air Soil Pollut Focus 6:625-636

Kondolf GM (1997) Hungry water: effects of dams and river mining on river channels. Environ Manag 21:533-551

Leopold LB (1997) Waters, rivers and creeks. University Science Books, California, USA

Major JJ, Pierson TC, Dienhart RL, Costa JE (2000) Sediment yield following severe disturbance- $\mathrm{a}$ two decade perspective from $\mathrm{Mt}$ St Helens. Geology 28:819-822

McDowell R, Sharpley A, Folmar G (2001) Phosphorus export from an agricultural watershed-linking source and transport mechanisms. J Environ Qual 30:1587-1595

Middelkoop H (2000) Heavy-metal pollution of the river Rhine and Meuse floodplains in the Netherlands. Neth J Geosc-Geol Mijnbouw 79:411-428

Middelkoop H, Erkens G, Van der Perk M (2010) The Rhine Delta-a record of sediment trapping over time scales from millennia to decades. J Soils Sediments. doi:10.1007/s11368-010-0237-z, this issue

Neary DG, Smethurst PJ, Baillie BR, Petrone KC, Cotching WE, Baillie CC (2010) Does tree harvesting in streamside management zones adversely affect stream turbidity? Preliminary observations from an Australian case study. J Soils Sediments this issue

Netzband A, Reincke H, Bergemann M (2002) The River Elbe: a case study for the ecological and economical chain of sediments. J Soils Sediments 2:112-116

Owens PN, Walling DE (2003) Temporal changes in the heavy metal and phosphorus content of suspended sediment transported by Yorkshire rivers, UK over the last 100 years, as recorded by floodplain deposits. Hydrobiologia 494:185-191

Petticrew EL, Owens PN, Giles T (2006) Wildfire effects on the composition and quantity of suspended and gravel stored sediments. Water Air Soil Pollut Focus 6:647-656

Slattery MC, Todd LM, Phillips JD, Breyer JA (2010) Holocene sediment accretion in the Trinity River Delta, Texas in relation to modern fluvial input. J Soils Sediments. doi:10.1007/s11368010-0232-4, this issue

Slaymaker O (2010) Drivers of mountain landscape change during the twenty-first century. J Soils Sediments. doi:10.1007/s11368-0100194-6, this issue

Søndergaard M, Jensen JP, Jeppesen E (2003) Role of sediment and internal loading of phosphorus in shallow lakes. Hydrobiologia 506-509:135-145

Van der Perk M, Owens PN, Deeks LK, Rawlins BG, Haygarth PM, Beven KJ (2007) Controls on catchment-scale patterns of phosphorus in soil, streambed sediment, and stream water. J Environ Qual 36:694-708 
Vanmaercke M, Zenebe A, Poesen J, Nyssen J, Verstraeten G, Deckers J (2010) Sediment dynamics and the role of flash floods in sediment export from medium-sized catchments: a case study from the semi-arid tropical highlands of northern Ethiopia. J Soils Sediments. doi:10.1007/s11368-010-0203-9, this issue

Vericat D, Batalla RJ (2006) Sediment transport in a large impounded river: the lower Ebro, NE Iberian Peninsula. Geomorphology 79:72-92
Viles HA, Naylor LA, Carter NEA, Chaput D (2008) Biogeomorphological disturbance regimes: progress in linking ecological and geomorphological systems. Earth Surface Processes Landf 33:1419-1435

Welch EB, Cooke GD (1995) Internal phosphorus loading in shallow lakes: importance and control. Lake Reservoir Manag 11:273-281

Williams GP, Wolman MG (1984) Downstream effects of dams on Alluvial Rivers. USGS Report. US Government Printing Office, Washington DC, USA 